\title{
FLUXOS TURÍSTICOS NA SOCIEDADE CAPITALISTA: MOTIVAÇÕES PARA A VIAGEM E CONSEQUÊNCIAS ESPACIAIS
}

\section{Tourism flows in capitalist society: motivations for travel and spatial consequences}

\author{
Nathan da Silva Nunes \\ Doutorando pelo Programa de Pós-Graduação em Geografia da UERJ \\ nunesuerj@gmail.com \\ Daiana Novaes Gouvêa \\ Mestranda pelo Programa de Pós-Graduação em Geografia da UERJ \\ daianangouvea@gmail.com
}

Artigo enviado para publicação em 14/05/2019 e aceito em 09/09/2019

DOI: $10.12957 /$ tamoios.2019.42709

\begin{abstract}
Resumo
O turismo se apresenta como importante atividade para a economia contemporânea, atuando na geração de riqueza para grupos capitalistas e modificando espaços urbanos e rurais, paisagens, territórios e lugares, o que o torna objeto de estudo da Geografia. Entretanto, o ato de viajar é anterior ao turismo, relacionando-se incialmente com motivações como o comércio, as guerras e a busca por conhecimento. O acréscimo do turismo às atividades que ocasionam fluxos populacionais ocorre com a ascensão capitalista e as transformações de condições no mundo do trabalho a partir do século XIX. O maior tempo livre conferido ao trabalhador é apropriado por essa nova atividade, que baseia suas práticas no consumo e no espetáculo. Nesse contexto, emergem motivações diversas para o ato de deslocar-se, como a busca por diversão e uma reconexão com o eu interior. A partir disto, o artigo objetiva analisar a construção do fenômeno turístico enquanto bem de consumo na sociedade contemporânea, evidenciando motivações que levam as pessoas a viajar e consequências espaciais desta prática. Para tanto, são utilizados referenciais que tratam da temática empírica e teoricamente, proporcionando o estabelecimento de um debate acerca da mesma.
\end{abstract}

Palavras-chave: Turismo; Viagem; Sociedade capitalista; Espaço; Consumo.

\begin{abstract}
Tourism presents itself as an important activity for the contemporary economy, acting in the generation of wealth for capitalist groups and modifying urban and rural spaces, landscapes, territories and places, which makes it an object of study of Geography. However, the act of travel is prior to tourism, relating initially to motives such as trade, wars and the search for knowledge. The increase of tourism to the activities that cause population flows occurs with capitalist rise and the transformations of conditions in the world of work from the nineteenth century. The greater free time conferred to the worker is appropriated by this new activity, which bases its practices on the consumption and the spectacle. In this context, diverse motivations emerge for the act of moving, such as the search for fun and a reconnection with the inner self. From this, the article aims to analyze the construction of tourism phenomenon as consumer good in contemporary society, showing motivations that lead people to travel and spatial consequences of this practice. For that, references are used that deal the theme with the empirical and theoretically, providing the establishment of a debate about it.
\end{abstract}

Keywords: Tourism; Travel; Capitalist society; Space; Consumption. 


\section{Introdução}

O turismo é uma atividade econômica que representa importante fonte de receita para países, regiões, estados, cidades e agentes do setor privado. $\mathrm{O}$ avanço das tecnologias relacionadas aos transportes facilitou os deslocamentos cada vez maiores e em menor tempo, o que auxiliou a expansão de destinos nas últimas décadas, sendo eles atrativos aos mais variados públicos. Informações divulgadas pelo Ministério do Turismo (2019) apontam para o crescimento de fluxos populacionais com esta finalidade em todo o mundo. Em termos internacionais, a partir de dados estatísticos da Organização Mundial do Turismo, o órgão brasileiro verificou a chegada de cerca de 1,4 bilhão de turistas estrangeiros em todo o planeta no ano de 2018. No que tange ao Brasil, os números ainda são pouco expressivos se comparados a outros países, tendo sido observada a entrada de 6,6 milhões de visitantes tanto em 2017 quanto em 2018.

A partir desta expressividade da atividade turística na atualidade, estabelecemos como objetivo para este artigo analisar a construção do fenômeno turístico enquanto bem de consumo na sociedade contemporânea e algumas motivações que levam as pessoas a viajar. Para tanto, nos basearemos na constatação realizada por Arnaud Champenois (2018, p.2), quando afirma que "as viagens tornaram-se o bem de consumo mais desejado. Descobrir o mundo, reconectar-se com o eu interior, comer e beber bem e divertir-se tem sido as prioridades de uma parcela significativa de consumidores".

A abordagem de Champenois afirma o turismo como bem de consumo que desperta maior desejo na sociedade capitalista contemporânea, além de evidenciar algumas motivações possíveis para que crescentes fluxos populacionais desloquem-se anualmente pelo mundo. Neste sentido, identificamos no fragmento acima ao menos dois aspectos distintos que servem como motivação aos deslocamentos na atualidade, que são as buscas por uma (re)conexão com o eu interior (a essência do sujeito) e pela diversão em locais distintos daqueles do cotidiano. Dessa forma, os elementos apresentados balizarão os segmentos nos quais este artigo está dividido, estando estes pautados em um viés geográfico do fenômeno.

Em sua primeira parte, discutiremos a origem das viagens, passando pelas fases de expansão comercial e de guerras, até chegar ao período de consolidação do turismo enquanto bem de consumo desejado por significativa parcela da população mundial, buscando identificar as implicações de viagens inseridas no contexto de uma sociedade na qual tudo é espetáculo e, por esse motivo, as visitas a determinados locais turísticos tendem a ser mais valorizadas por sua aparência que propriamente pela essência.

Na segunda seção começaremos a abordar a temática do turismo a partir de motivações que originam as viagens. Neste segmento a discussão será pautada nos deslocamentos que tem como motivação a busca pelo reestabelecimento de um contato perdido com sua identidade original, distinta daquelas que possuímos e apresentamos ao estabelecer contato com o mundo exterior no cotidiano, especialmente na vida em grandes cidades.

Por fim, a discussão tratará das viagens turísticas em busca de diversão, procurando identificar as diversas maneiras de atuação dos agentes do setor e as implicações espaciais quando da criação de locais destinados a este fim.

A metodologia da pesquisa consiste no levantamento bibliográfico de publicações que abordam a relação entre a Geografia e o Turismo, a origem das viagens de maneira ampla, além daquelas que apresentam as especificidades na constituição de locais com fins turísticos e das motivações que ocasionam os deslocamentos. 


\section{A inserção do Turismo na sociedade do consumo e do espetáculo}

Para que possamos discutir o Turismo na atualidade e as relações do mesmo com a ciência geográfica, é importante que compreendamos as origens dessa vontade/necessidade de grandes deslocamentos praticados pelo ser humano. Nesse sentido, recorremos a Ambrózio (2005), para quem as viagens atravessam a história, tendo sido a motivação comercial uma das primeiras, e que ainda se mantém na atualidade.

Os fenícios foram os primeiros a romperem com a tradição do comércio terrestre, navegaram por todo o Mediterrâneo fundando feitorias e estações (...); os espanhóis viajaram para, violentamente, despojarem a América do Sul; a Liga Hanseática fundara em toda a Europa norte e oriental escritórios (...); até os índios ribeirinhos da bacia amazônica do século XVI dão evidências da viagem de longa distância comercial, ou de troca (p.105).

Além das razões comerciais, as guerras apresentam-se como outro fator recorrente para os deslocamentos populacionais ao longo da história humana, como a travessia do rio Niemen pelo exército napoleônico em 1812. Outras grandes viagens foram realizadas com propósito educacional em direção, por exemplo, a países europeus e da América do Sul, como no caso de Alexander Von Humboldt. Wulf (2016, p.25) descreve a visão de mundo do geógrafo alemão e sua necessidade pela descoberta de locais distantes ao afirmar que, ainda na juventude, ele "participou de uma experiência científica de cinco anos pela América Latina, arriscando a vida muitas vezes e voltando para casa com uma nova noção sobre o mundo". A autora descreve ainda sua percepção de mundo e da ciência, diferenciando-o de outros pesquisadores, visto que

fascinado por instrumentos científicos, medições e observações, era igualmente movido por um senso de deslumbramento e encantamento. Claro que a natureza tinha de ser medida e analisada, mas ele acreditava também que grande parte de nossa resposta ao mundo natural deveria se basear nos sentidos e nas emoções (WULF, 2016, p.27).

A partir disso, podemos perceber que mesmo quando as motivações são semelhantes, o ato de viajar e a maneira com que o sujeito vai se relacionar com o local desconhecido dependerá de suas próprias concepções de mundo.

Contudo, a partir do século XIX os grandes deslocamentos têm um novo sentido a eles acrescido, o turismo. Surgido em 1811 na Inglaterra, o termo ganha força ao fim da primeira metade do referido século, quando é criada a primeira agência de viagens naquele mesmo país. Podemos compreender através da abordagem de Ambrózio (2005, p.106) que o turismo, desde sua origem, caracteriza-se como "prática social acoplada à produção de mercadoria, designando a conversão da viagem a um fim em si”.

Aliado à aquisição de direitos trabalhistas no pós-Segunda Guerra Mundial, o turismo ganha maior notoriedade com a criação de uma ideologia capitalista que propaga a necessidade de consumo do tempo do não-trabalho e com o fenômeno da globalização, que facilita o acesso a locais distantes e até então desconhecidos (MESQUITA, 2006). Nesse momento, com a expansão do sistema de produção fordista, as populações, especialmente nos países desenvolvidos, passam a ter acesso a uma enorme quantidade de produtos e localidades, fazendo com que o consumo destes seja ressaltado como verdadeira demonstração de status social (VARGAS, 2016).

No que diz respeito à Geografia, as práticas inerentes aos agentes turísticos fornecem uma gama enorme de possibilidades de pesquisa, visto que as implicações da 
atividade podem atuar diretamente na formação de redes, na (re)produção de espaços urbanos e rurais, na destituição e constituição de territorialidades, na transformação da aparência e essência de paisagens, na alteração do sentido de lugar para populações residentes e em diversos outros aspectos relevantes aos profissionais desta ciência.

Para tratar da produção e consumo do espaço turístico, recorremos a Ribeiro (2006), o qual destaca a configuração dos ambientes urbanos como preferenciais para a atuação dos agentes capitalistas, incrementando as dinâmicas que configuram estes espaços. Tal abordagem dialoga com as concepções de Paiva (2016a, p.38), que conclui estarem a produção e o consumo do espaço turístico inseridos no processo de acumulação capitalista, ocupando "uma posição de destaque no processo de acumulação pósindustrial sob a égide do consumo", sendo visíveis na diversidade de bens, mercadorias e serviços oriundos de setores que servem ao turismo, como os transportes e a hotelaria. No que tange às práticas políticas, verifica-se a penetração de iniciativas neoliberais no planejamento das cidades, notadamente no que diz respeito à promoção da competitividade entre elas (PAIVA, 2016a).

O processo de neoliberalização, de acordo com Harvey (2014, p.13), envolve práticas de destruição criativa, seja dos poderes e estruturas institucionais ou também das "divisões do trabalho, das relações sociais, da promoção do bem-estar social, das combinações de tecnologias, dos modos de vida e de pensamento, das atividades reprodutivas, das formas de ligação à terra e dos hábitos do coração". Neste contexto, Panosso Netto et al. (2016), ao relacionarem este cenário com a atividade turística, atestam a existência uma crise de valores culturais, humanos, morais e éticos, que fará com que o turismo prime pela mercantilização da cultura e pela perda de valor da vida humana. Recorrendo a outros pensadores, os autores reafirmam nossa condição enquanto sujeitos inseridos na sociedade do espetáculo, esta que se relaciona de maneira direta com o turismo, entendido recorrentemente como fenômeno puramente econômico. A percepção da atividade turística por um viés que desconsidera as relações sociais nela presentes seria, portanto, um fator limitante para o "desenvolvimento das teorias atuais e na própria prática de um turismo mais justo e responsável" (PANOSSO NETTO ET AL., 2016, p.165).

De maneira complementar, Bessa e Álvares (2014, p.47) também evidenciam suas preocupações acerca das consequências provocadas pela atividade em tela, ao tratarem das intervenções urbanas, paisagísticas e arquitetônicas observadas nas últimas décadas em função do turismo, ressaltando que possuem uma capacidade singular de transformar territórios, "contribuindo para dar novo caráter às suas paisagens que, transformadas em mercadorias, passam a necessitar de constantes mudanças para (re)(con)figurar o mundo que o espetáculo apresenta".

A sociedade atual, pautada no incentivo e valorização do consumo, tem o turismo como elemento primordial, em função da necessidade criada de vivência de experiências e locais diferentes daqueles da vida cotidiana. Nesse sentido, o consumo de objetos icônicos tem obtido destaque nas últimas décadas, passando a ser (re)valorizados fixos antigos, como a Torre Eiffel, "concebida como estrutura provisória (...) que, por sua forma, arrojo, verticalidade e inserção urbana, converteu-se em um dos ícones urbanos e arquitetônicos mais significativos da história" (PAIVA, 2016b, p.294) ou sendo criadas novas monumentalidades que atraem por suas formas arrojadas, como o Museu do Amanhã, localizado na zona portuária do Rio de Janeiro, estabelecendo marcos na paisagem e evidenciando as transformações socioespaciais importantes de determinadas épocas.

Sendo assim, as localidades tendem a ser incorporadas pelo turismo como cenários de consumo, onde comumente percebemos a valorização da superficialidade das formas 
em detrimento das funções exercidas. Tal condição é influenciada diretamente "pelos avanços tecnológicos na produção e divulgação de imagens, associadas à lógica do consumo dos lugares" (PAIVA, 2016b, p.299). De acordo com Nunes (2017), a dominação pelas imagens a qual somos submetidos faz com que não tenhamos a capacidade de interpretá-las de maneira adequada, consumindo-as a partir de interpretações prévias dos grupos que as divulgam. As representações, especialmente aquelas criadas através da fotografia, passam a estar presentes em toda parte (WOLF, 2005), o que eleva o ícone a condição de uma das maiores contribuições da arquitetura ao mundo moderno, pautado na lógica do espetáculo.

\begin{abstract}
Assim, no mundo da mercadoria, o espetáculo torna-se sinônimo de cultura, o centro de significação de uma sociedade sem significação, ideologia materializada sobre a vida dos homens (...). O espetáculo torna-se, pois, o reino da mercadoria, reduzindo a cultura a seu mais alto grau de alienação, reino da passividade absoluta do indivíduo" (NOVAES, 2005, p.9).
\end{abstract}

O turismo encontra-se totalmente inserido nesta lógica, na qual é muito mais regra que exceção o consumo superficial e mercadológico. As imagens representativas de espaços urbanos e rurais valorizados socialmente atuam na promoção de locais, bem como para elevação do status social de turistas que por lá tenham passado. Para Bucci (2015, p.219) "o capitalismo atual tem sua mercadoria antes na imagem da coisa do que na coisa corpórea. É como imagem que a mercadoria circula. É sua imagem que precipita seu consumo". Complementarmente, Jappe (2005, p.255) se vale do conceito de sociedade do espetáculo trabalhado por Guy Debord para afirmar que vivemos em uma "sociedade baseada na contemplação passiva, em que os indivíduos, em vez de viverem em primeira pessoa, olham as ações dos outros".

Este processo de produção e circulação de imagens representativas de locais valorizados pelo turismo auxilia na confecção de um imaginário a respeito dos mesmos. Nesse sentido, Duarte (2005) alerta para a manipulação comportamental realizada pelos agentes capitalistas. Essa discussão também é empreendida por Jappe (2005), quando este autor afirma que a mercadoria está presente em cada esfera da vida, estando o desejo de consumir determinada bebida, roupa ou mesmo destinos turísticos condicionado pela publicidade que se faz dos mesmos.

O espetáculo é o momento em que a mercadoria ocupou totalmente a vida social. Não apenas a relação com a mercadoria é visível, mas não se consegue ver nada além dela: o mundo que se vê é o seu mundo. A produção econômica moderna espalha, extensa e intensivamente, sua ditadura (DEBORD, 1997, p.30).

Dessa forma, entendemos caber ao marketing turístico a promoção de destinos, formando a partir de então uma imagem positiva da cidade, que poderá ou não ser constituída de informações verdadeiras. Tais estratégias têm sua importância acentuada em um contexto de competição global, na qual as técnicas utilizadas na divulgação de destinos atuam para diminuir possíveis receios dos turistas, valorizando apenas as qualidades de cada localidade. Isto ocorre, pois é através desta imagem positiva que a localidade tornar-se-á atrativa. Correa (2010) afirma ser esta uma política recorrente nos últimos anos para países, regiões e cidades que buscam participar do comércio internacional a partir da atividade turística.

Como já mencionado, o conjunto da sociedade é sufocado pela atuação da publicidade turística, acabando os sujeitos convencidos da necessidade de viajar com certa frequência para aqueles locais selecionados e valorizados pelos agentes capitalistas 
em cada período. Da mesma forma, a modalidade de turismo a ser praticada já se encontra estabelecida socialmente através de modelos de comportamento que serão encaixados ao estado de espírito dos sujeitos a cada viagem.

Para Claval (2010), há diversos motivos que levam as pessoas a viajar, desde a busca por emprego e novos clientes, passando pela tentativa de testar o próprio corpo. Entretanto, o autor invoca como uma das principais motivações a necessidade de escapar do ritmo infernal da vida cotidiana, especialmente nas grandes metrópoles, ou seja, o deslocamento com fins turísticos.

\begin{abstract}
Eles ficam felizes de evoluir numa natureza autêntica, em meios não poluídos. Há outros que querem conhecer as maravilhas do mundo, aquelas das quais sempre ouviram falar (...). Muitos partem pelo prazer de seguir os passos dos homens célebres, de percorrer o meio ambiente nos quais evoluíram as vedetes do cinema ou as estrelas do cinema, de visitar os lugares onde a história se fez, onde as grandes batalhas foram ganhas ou perdidas, onde as revoluções tiveram início e se desenvolveram. A preocupação de descobrir as obras primas do passado, os edifícios construídos pelos arquitetos célebres, os escultores e as pinturas que os grandes museus encerram, o ambiente das cidades de arte e de história (CLAVAL, 2010, p.48-49).
\end{abstract}

Duas motivações encontradas na sociedade contemporânea para que as pessoas viajem serão temas dos próximos segmentos deste artigo. Discutiremos a procura por uma (re)conexão com o eu interior e por diversão, destacados na abordagem de Champenois, evidenciando as singularidades de cada uma destas motivações.

\title{
Turismo em ambientes rurais e religiosos: a busca por uma reconexão com o eu interior
}

O desejo por reconectar-se com o eu interior é uma das atividades em evidência nos dias atuais, seja através da aproximação com a natureza ou pelo contato com o sobrenatural através das religiões. Esse modo de turismo, em primordial, pode ser caracterizado pela busca de sensações que os lugares ou rituais possam oferecer. $\mathrm{O}$ inusitado, o contato com outras culturas e modos de vida tem atraído olhares do cidadão urbano que procura a experiência de vivenciar o novo. Nesse sentido, abordaremos aqui duas vertentes do turismo que visam uma reaproximação consigo mesmo: o turismo rural e o turismo religioso.

O turismo rural, de acordo com Souza et al. (2019, p.24), origina-se da busca por "diferentes experiências de férias por parte dos turistas, tornando-se uma possibilidade de atividade turística que contempla aspectos culturais, naturais e emocionais". Tal segmento tem crescido nos últimos anos em prol de alternativas econômicas para o campo, o qual deixa de ser exclusivamente agrícola e apresenta uma pluralidade de atividades, de modo a garantir diversas formas de complementação de renda (RIBEIRO e SILVA, 2006). A partir dessa necessidade, modalidades de turismo são fomentadas, tendo como diferencial a inserção do visitante no modo de vida rural em contato com a natureza, permitindo uma recepção personalizada, introduzindo a participação dos visitantes nas atividades e costumes da população local, interagindo com os mesmos e conhecendo seus hábitos e crenças.

De acordo com o Ministério do Turismo (2010), tal modalidade surge com maior destaque em países europeus e nos Estados Unidos, passando a ter relevância no Brasil na década de 1980. A proliferação dessas atividades atribuiu em alguns casos um complemento de renda e a inserção dos produtores familiares em atividades não agrícolas, gerando mais empregos, contribuindo para a redução do êxodo rural e, também, 
auxiliando na preservação dos valores socioculturais do indivíduo no meio rural. Em outros casos, o cenário se modifica e as populações locais acabam alijadas do processo ou participam de maneira reduzida.

Os turistas que optam por conhecer um ambiente rural, em geral, procuram maior afastamento de sua rotina e do que possa conectá-lo a ela, contudo, segundo Ruschmann (s/d), o fazem sem abdicar de um conforto razoável se comparado àquele do seu cotidiano, o que por sua vez exige uma adaptação das propriedades e comunidades rurais às necessidades dos turistas urbanos. Ainda segundo a autora (s/d),

é necessário associar os serviços receptivos prestados aos turistas às demais atividades produtivas do empreendimento, proporcionando o conforto e a experiência vivencial - que o turista vem buscar - sem descaracterizá-la, sob pena de tornar-se apenas mais um equipamento do turismo convencional.

O exotismo que essa experiência oferece é característica de uma identidade própria do campo, destacando-se das demais atividades do mercado turístico. É preciso que o comprometimento das comunidades rurais vá além de uma necessidade de estimular a economia, mas que considere protagonizar o modo de vida no campo, sua cultura e costumes, e o contato direto com a natureza, gerando identificação do visitante com o ambiente natural e se apresentando a ele como um bem que precisa ser conservado e preservado. A assimilação da importância do ambiente natural para a manutenção da vida pode estimular a criação de laços, estabelecendo a consciência da educação ambiental, através da identificação do turista com o lugar.

Neiman (2008) nos chama atenção para a necessidade de uma educação ambiental realizada através do contato com o campo, pela necessidade de conscientização da preservação ambiental. Além do turismo rural, o ecoturismo também deve ser destacado neste contexto, visto que tem sido divulgado e propagado, oferecendo além de uma viagem exótica, também a venda de sensações, um contato não só com a natureza como também um alívio para alma. Nesse sentido a autora (2008, p.39) complementa ao dizer que

o ecoturismo, com suas caminhadas "arriscadas" no meio da mata, e o romantismo provocado pela aproximação com a natureza (quase como um ato religioso) são muito valorizados atualmente. O campo é mitificado e serve de escape, compensação à vida complicada da cidade.

O modo de vida distinto ao vivenciado no cotidiano impulsiona o turista a expandir suas experiências e buscar novas sensações através de paisagens e culturas até então desconhecidas, ainda que a intenção fundamental seja sensibilizar o visitante a importância do ambiente rural, faz-se necessárias providências para assegurarem os impactos causados na natureza através da atividade exploratória desse recurso.

O turismo religioso, definido por Dias (2003, p.17) como "aquele empreendido por pessoas que se deslocam por motivações religiosas e/ou para participarem em eventos de caráter religioso", se fundamenta em uma intencionalidade semelhante a do turismo rural, sendo caracterizados pela busca das sensações, do sagrado e do imaterial, aspectos de difícil acesso no cotidiano. Essa modalidade de turismo é classificada como vertente emergente no quadro de estudos turísticos, apesar de ser praticado em escala mundial, surgindo com maior intensidade na Europa do pós-guerra, viabilizado a partir de fatores como a popularização das viagens de automóvel (SANTOS, 2006). Segundo Manssur (2003, p. 56), se referindo a aspectos de planejamento e investimentos, o que faz com que atualmente possa ser caracterizado como turismo de massa, "as viagens com motivação 
religiosa só vieram a se tornar turismo religioso quando o volume de pessoas envolvidas alcançou uma escala que tornou economicamente viável".

Ao tratar sobre essa temática, encontramos em diversos autores como Santos (2006) e Alves (2003) a diferenciação entre o turista religioso e o peregrino, estabelecendo limites vitais para a compreensão desse mercado turístico. Ao distinguilos, podemos entender a peregrinação como o ato de percorrer o caminho sendo mais importante do que a vivência no local de destino, buscando, primordialmente, a experiência religiosa. A motivação do peregrino se diferencia do turista quando neste existe também a procura pelo imaterial e simbólico, diferenciando-se de acordo com a intensidade da motivação e a forma com que ela se materializa.

Santos (2006) apresenta uma linha conceitual que comporta gradações ligadas ao interesse primário, a qual diferencia o peregrino do turista. $\mathrm{O}$ turista procura conjugar o prazer com a fé, sendo sua maior motivação o ato de viajar, de desbravar novos lugares, movido pela religião, enquanto o peregrino é movido essencialmente pelo sagrado. Apesar da intensidade de devoção diferenciar esses dois tipos de viajantes, a classificação acontece de forma imprecisa, pois é definida pelo sentimento e busca particular de cada um.

É no viajante que intenciona não só o sagrado que o mercado turístico atua, fornecendo uma diversidade de atividades em locais religiosos para uma maior atratividade e experiência ao visitante. Nesse sentido o turista religioso procura aliar o prazer com a fé, a religião com o lazer, o sagrado e com o profano. Essas motivações são apresentadas nas dimensões turísticas das festividades religiosas, as quais "coloca seus participantes em contato com uma cadeia de símbolos e de sentidos que sustentam a cultura em que estão imersos" (COSTA, 2003).

O espaço, objeto primordial da ciência geográfica, ganha conotação religiosa a partir da hierofania, classificada por Costa (2003, p. 183) como uma verdadeira "manifestação do sagrado que se revela como uma realidade de ordem inteiramente diferente das realidades do cotidiano. $\mathrm{O}$ fenômeno do milagre é considerado como fator primordial para a emergência dos espaços sagrados". Logo, o turismo religioso se instaura na busca dos fiéis pelos lugares sagrados, com a intencionalidade de manifestar sua fé e cumprir sua devoção para estabelecer um sentimento de paz consigo mesmos. A significação religiosa e mística transforma o espaço, agregando sentido religioso a este, tornando-o um núcleo representante da fé de determinado segmento religioso.

Ao mercado turístico cabe, também, a venda desses lugares enquanto destino turístico, viabilizando a chegada dos fiéis até o espaço religioso, assim com uma rede de serviços, como hospedagem, alimentação e venda de artigos religiosos. Essa vertente do turismo, embora possa não dispor da mesma visibilidade de outras, é um dos ramos mais sólidos, sendo caracterizada pela busca do sagrado, necessidade inerente ao ser humano, e pelo viés cultural intrínseco ao turismo religioso.

A proximidade com o sagrado proporciona a muitos fiéis não apenas a possibilidade de estar em contato com seus deuses e santos, mas, acima de tudo, viabiliza momentos de reflexão e paz interior. As dificuldades vividas no cotidiano são analisadas com a serenidade proporcionada pelo local embebido na fé e a crença na resolução de tais problemas geram maior tranquilidade para que sejam enfrentados.

O sentido das viagens para ambientes rurais e religiosos apresentam forte relação com questões pessoais e a busca por reflexão, distinguindo-se profundamente das modalidades turísticas nas quais a diversão é o principal objetivo, como poderá ser verificado no próximo segmento. 


\section{O turismo nos espaços-mercadoria destinados à diversão}

Um dos itens mencionados por Champenois (2018) na citação que norteia esta pesquisa, de notória relevância e de grande demanda no ramo do turismo, diz respeito a procura pela diversão, manifestada de diversas formas em distintos lugares. Devido a fatores abordados na primeira parte do artigo, a ideia de diversão se tornou fundamental para a vida dos indivíduos, sendo indispensável para o que se entende socialmente por uma vida feliz e saudável. Essa modalidade de turismo é facilitada pelas leis trabalhistas que asseguram ao empregado um tempo destinado ao ócio, o tempo livre. É em prol desses indivíduos que o turismo se apresenta com uma nova característica do que fora apresentado até o momento nesse artigo, a busca pelos serviços de diversão e entretenimento.

Faz-se necessário evidenciar uma das principais características inerentes a este modelo de turismo, que é a procura majoritária pelo ambiente urbano. Ao optar por esta modalidade, o viajante espera encontrar um ambiente que disponha de tecnologias e conforto. Essa característica se apresenta como um diferencial quanto ao modelo turístico exposto anteriormente, no qual buscava como prioridade o desconectar-se do mundo, das rotinas e busca reconectar-se com o eu interior.

Para uma melhor compreensão de tais práticas turísticas, serão abordadas três modalidades, divididas a partir da frequência com que ocorrem, sendo elas: os espaços turísticos permanentes em uma determinada localidade com a finalidade da diversão; aqueles que surgem de forma periódica a partir da realização de eventos específicos, realizados em um mesmo local com determinada frequência; e os que são produzidos de maneira pontual, através de eventos que podem acontecer apenas uma vez ou com periodicidade de décadas ou séculos. As diferenciações dessas temporalidades auxiliam no entendimento dos impactos a ela relacionados no que diz respeito ao espaço. Segundo Mesquita (2006, p. 4) "o aparecimento do fenômeno do turístico reorganiza o lugar, redimensionando as esferas econômicas, políticas e socioculturais e afetando sobremaneira a sua organização espacial".

O mercado turístico que se apresenta, em um primeiro momento, pela busca do entretenimento, é evidenciado por cidades que oferecem ao turista infraestrutura voltada para o lazer, que podem ser representadas por parques, exposições, festivais de música e gastronômicos, eventos esportivos etc. Esses destinos turísticos por vezes reúnem viajantes de diversos países, e, por consequência, são divulgados como atração em veículos midiáticos ao redor do mundo. Essas atrações são responsáveis por parte considerável do mercado turístico, os quais atuam na divulgação do evento, agências que promovem maior acessibilidade até o local e um mercado hoteleiro voltado para esse público.

Para elucidarmos como são concebidos os diferentes atrativos turísticos voltados para a diversão, em um primeiro momento apresentaremos a modalidade de atrativos permanentes no espaço, que estão inseridos em um determinado local e recebem fluxos turísticos ao longo de todo o ano. A fim de exemplificação, podemos citar o parque temático Walt Disney World Resort (figura 1), com sede no Estado da Flórida, em Orlando, fundado em 1971 por Walt Disney e Roy Disney. Nesta cidade se encontram atualmente parques temáticos que ilustram/representam os filmes produzidos pelos estúdios Walt Disney; o parque aquático onde, além de brinquedos e piscinas, são oferecidas aos visitantes experiências como nadar com golfinhos; restaurantes com alimentos temáticos e característicos do parque; comércios de vestuário e acessórios, também temáticos; e resorts que hospedam o turista em área do próprio parque. Esses atrativos fornecem a experiência de conhecer esse mundo "encantado" divulgado à 
exaustão nos veículos midiáticos há décadas, produzindo um expansivo mercado turístico local, o qual conta com cerca de 148 milhões de visitantes ao ano, distribuídos pelos onze parques da Disney espalhados ao redor do mundo, segundo reportagem da revista Abril de 2016. Ambrózio (2005, p.109) complementa a respeito ao dizer que

sem o circo e pão a vida não se realizaria. Espaços turísticos exemplares como a Disneylândia, transatlânticos, Epcot center, resorts e outros mais, estariam ligados ao divertimento reprodutor da capacidade de trabalho no interior do capital. Espaços-mercadoria assim constituídos são consequências da sociedade de massas que, necessitando de diversão, consumiria o espaço como mercadoria biológica.

Figura 1 - Folder com pacote de viagens para Walt Disney

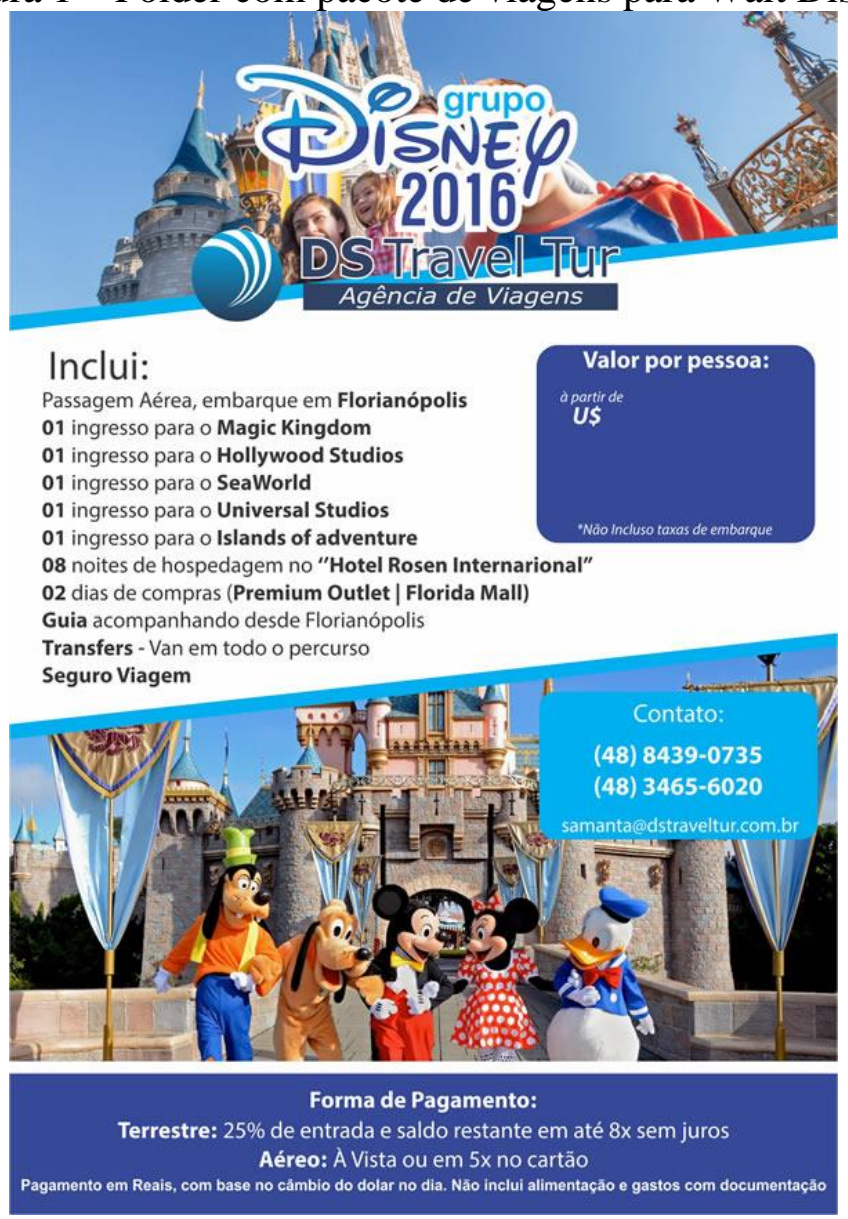

Fonte: DS Travel turismo, 2016.

Na América Latina, esta modalidade turística pode ser evidenciada, entre outros locais, em praias da região Nordeste do Brasil e Cancún, onde o fluxo de viajantes em busca do sol e praia é expressivo, não só recebendo visitantes do próprio país, como estrangeiros que tem seu acesso facilitado por meio de agências turísticas. Limonad (2008, p. 133), evidencia as "ações implementadas pelo governo federal para conectar capitais do Nordeste do Brasil a algumas cidades europeias". Essas medidas, tomadas para intensificação turística, acarretam, segundo a autora (2008, p. 135) em "uma multiplicação desordenada de condomínios e resorts internacionais, com a criação de bolhas turísticas internacionais e a exclusão social dos antigos habitantes".

Ao frequentar locais como estes, o turista recorrentemente tem contato restrito com a cidade ao redor dos resorts em que se hospeda e demais atrativos que visita. As 
agências de viagem promovem o deslocamento e estadia em área própria dos estabelecimentos, ofertando todo tipo de consumo ao visitante. Nesse sentido, o caso da cidade mexicana de Cancún é singular, pois a criação da região turística objetivava desde sua concepção o isolamento em relação ao que a cerca, excluindo parcialmente a população local da dinâmica turística, visto que estes participam apenas ao oferecer sua mão de obra. Fuentes (2001, p.116) ao descrever como se deslocam os fluxos turísticos neste local aponta que

a inovação consiste no turista que chega a zona hoteleira diretamente do aeroporto e não se inteira de onde está a cidade, totalmente separada. As pessoas da cidade viajam até a zona hoteleira para trabalhar e não tem praticamente nenhuma relação entre a população residente e os turistas.

Este atrativo de caráter permanente estabelece um fluxo turístico, com variações ao longo do ano, promovendo destaque e rentabilidade para um determinado local. Além dessa característica, é preciso destacar que essa modalidade de atrativo exige infraestrutura diferenciada na localidade em que se encontra, como vias de acesso permanente, voos direcionados a este fim, rede hoteleira que atenda as necessidades e demandas desse público. Outro fator de destaque no turismo no qual a diversão é o principal objetivo são os impactos causados para os residentes quanto ao valor e uso do solo, assim como para a vegetação nativa, não se fazendo primordial o planejamento e gestão ambiental.

Os atrativos que são produzidos espacialmente de forma esporádica impactam de maneira diferenciada se comparados ao modelo anterior. Por se tratarem de eventos que ocorrem em curtos períodos de tempo em um mesmo local, o fluxo turístico é pontual, exigindo da localidade receptora uma série de alterações para viabilizar o evento. Como exemplo desse perfil turístico, podemos considerar os festivais musicais que mantém um público assíduo, como o Rock in Rio, realizado tradicionalmente na cidade do Rio de Janeiro (e ocasionalmente também em Lisboa e Madrid) e o Lollapalooza, que acontece em diversas cidades do mundo, e que no Brasil é sediado na cidade de São Paulo. Para esses eventos são montadas arenas com palcos e atrações de nível internacional ao longo de poucos dias. Os eventos recebem turistas de diversas origens, e além dos shows contam também com uma série de atrativos de entretenimento, como parques em seu interior. A cidade durante esses eventos sofre impacto em variadas instâncias, alterando sua dinâmica, como o aumento de contingente nos meios de transporte e a necessidade de reforço quanto à segurança pública no entorno das áreas em que o evento é realizado. Tais festivais não fazem parte do roteiro turístico em todas as épocas do ano, por isso contam com infraestrutura adaptada no período do seu acontecimento, não gerando renda permanente e, por vezes, não exigindo da cidade que o sedia infraestrutura e serviços definitivos.

Por outro lado, é comum que estes eventos sejam idealizados com a finalidade de desenvolver o turismo em épocas de pouco fluxo, a fim de aquecer o mercado turístico em períodos em que normalmente as cidades estariam esvaziadas, como o caso de Armação dos Búzios, conhecida internacionalmente pelo turismo de sol e praia. O município, onde primordialmente tem sua renda estabelecida pelo turismo, realiza no inverno o Festival Gastronômico de Búzios, por uma necessidade de manter uma constância do fluxo populacional, promovendo o evento com uma série de restaurantes cadastrados oferecendo aos visitantes grande diversidade no ramo gastronômico. Dessa forma, torna dinâmica a cidade e expande o mercado turístico da diversão.

Por fim, ao tratar sobre os eventos temporários, apontaremos a importância desse tipo de atrativo para a publicidade que se realiza a respeito do local, o que acontece pelo 
caráter excepcional dos mesmos. Esta modalidade de turismo tende a impactar ainda mais o local que o sedia, pela singularidade inerente a ele, exigindo da cidade organização para viabilizar a atração.

A demanda para sediar tais eventos e receber os fluxos oriundos dessa categoria de turismo eventual tem sido expressiva para o consumo do espaço capitalista, com a finalidade de obtenção de visibilidade no mercado, objetivando a geração de renda para uma determinada localidade. A partir disso, devemos considerar que a estratégia de marketing realizada por esse tipo de turismo esporádico se insere no contexto da competitividade entre os lugares, utilizando esses eventos pontuais como incremento no faturamento e uma maior evidência do local.

Nesse contexto, se inserem os eventos esportivos internacionais, que se apresentam no cenário mundial como importantes veículos de visibilidade, fluxos turísticos e investimento, como os Jogos Olímpicos de verão e de inverno, a Copa do Mundo de Futebol, os Jogos Pan-americanos, a Eurocopa de futebol, entre outros. Dada essa importância, as práticas turísticas relacionadas a estes acontecimentos tendem a impactar ainda mais o local sede, a partir da complexidade e contingente turístico esperado, resultando, em geral, em repercussões mais expressivas quanto à propagação do destino. A divulgação do local não se restringe às arenas onde são disputados os jogos, mas também aos espaços que recebem eventos paralelos associados à competição. A expressão espacial turística se apresenta autêntica enquanto "cria, transforma e, inclusive, valoriza diferencialmente espaços que poderiam não ter nenhum valor no contexto da lógica de produção" (NICOLAS, 2001, p.49).

O turismo designado a atender a demanda da diversão tem por alicerce a sociedade de consumo que busca novos produtos e serviços destinados ao lazer como forma de suprir a necessidade de novas aquisições, sejam elas materiais ou imateriais. Nesse sentido, Bertoncello (2001, p. 129) acrescenta ao afirmando que os produtos e serviços com finalidade recreativa "constituem um núcleo praticamente inesgotável de tal incitamento, na medida que esses produtos, baseados em recursos intangíveis, podem ser criados e recriados permanentemente, e consumidos diversas vezes".

\section{Considerações finais}

O ato de viajar não é novo para o ser humano. Como pudemos verificar, tais práticas são antigas, porém o que tem apresentado significativa transformação é sua finalidade. Se anteriormente os deslocamentos eram o meio para realizar transações comerciais, guerrear ou adquirir conhecimento, a partir do século XIX a viagem transforma-se a partir do turismo. As modificações na legislação trabalhista em países desenvolvidos conferem ao trabalhador maior tempo livre, que com a ascensão capitalista, viria a ser apropriado na reprodução do capital. Inserido em uma sociedade pautada pelo consumo, o turismo baseia-se na mesma lógica, e a viagem é transformada em necessidade/desejo no imaginário social.

Como prática espacial, o turismo modifica profundamente as localidades onde se instala, seja ela urbana ou rural. Nesse contexto, uma das práticas em evidência tem sido a inserção de objetos icônicos, os quais têm a superficialidade de suas formas transformada em verdadeiro cenário de consumo. A evolução técnica dos meios de comunicação exerce grande influência neste processo, visto que a criação de representações a partir de fotografias, filmes, propagandas de televisão e diversas outras mídias divulgam os ícones pelo mundo. A viagem com frequência é então compreendida como mecanismo de elevação do status social, visto que o ato de conhecer determinados locais e seus fixos famosos não está ao alcance de todos. 
A abordagem de Arnaud Champenois evidencia este cenário ao atestar que o turismo é o bem de consumo mais desejado na atualidade, além de apresentar algumas motivações alegadas para que as pessoas viagem na atualidade. A busca por uma conexão com o eu interior apresenta-se como consequência da vida nas cidades, caracterizadas muitas vezes pela monotonia paisagística, a falta de tempo e o stress. Com isso, busca-se o turismo em espaços rurais e religiosos, onde a publicidade vende as ideias de tranquilidade, beleza e contato com o sagrado. Com frequência, as transformações impostas a esses locais afetam diretamente a vida das populações locais, que tem negado qualquer poder de participação quando da inserção da atividade.

Outra motivação para os deslocamentos populacionais com fins turísticos é a busca pela diversão em locais onde predomina o turismo de sol e praia, a realização de festivais de música, megaeventos esportivos ou onde estão localizados parques temáticos. O que podemos observar nestes casos é, novamente, a maneira precária com que os residentes locais se inserem no processo, tendo sua importância reduzida à oferta de mão de obra. Além disso, a globalização tem atuado no sentido de padronizar a oferta, como pode ser observado no caso da Disney, que atualmente já possui onze parques pelo mundo.

Como já mencionado, o desejo de viajar é antigo para o ser humano, porém entendemos que na atualidade o ato de deslocar-se é influenciado em todas as esferas pela sociedade capitalista. Desta forma, a superficialidade com que a atividade é vendida, recorrentemente restringe seu sentido ao espetáculo, onde a aparência dos locais e práticas turísticas tende a ser mais valorizada que sua essência.

\section{Referências bibliográficas}

AMBRÓZIO, Júlio. Viagem, Turismo, Vilegiatura. In: GEOUSP - Espaço e Tempo, São Paulo, nº 18, pp. 105-113. 2005.

BERTONCELLO, Rodolfo. El Turismo Emissivo Argentino y sus Consecuencias Internas. Revista GeoUruguay. No5, 2001.

BESSA, Altamiro Sérgio Mol; ÁLVARES, Lúcia Capanema. As estratégias de empresariamento das cidades. In: MESSA, Altamiro Sérgio Bol; ÁLVARES, Lúcia Capanema. A construção do Turismo - Megaeventos e outras estratégias de venda das cidades. Belo Horizonte: C/Arte, 2014.

BUCCI, Eugênio. O espetáculo e a mercadoria como símbolo. In: NOVAES, Adauto (org.). Muito além do espetáculo. São Paulo: Editora SENAC, 2005. P.218-232.

CHAMPENOIS, Arnaud. "Conte algo que não sei”. O Globo, 23 de março de 2018. Disponível em: https://oglobo.globo.com/sociedade/conte-algo-que-nao-sei/arnaudchampenois-especialista-em-mercado-hoteleiro-de-luxo-voce-deve-viver-sua-marca$\underline{22519601}$. Acesso em: 15 de agosto de 2018.

CLAVAL, Paul. Viajar. In: Terra dos Homens: a Geografia. Editora Contexto, 2010.

CORREA, Ana. Las Ciudades y el Turismo em el Nuevo Escenario Internacional. In: Ciudades, Turismo y Cultura. Editora La Crujía Ediciones. 2010, pp. 21-32. 
$\overline{\text { COSTA, Otávio José Lemos. A festa do Senhor do Bonfim em Icó-CE: uma proposta de }}$ turismo religioso. In: Da Cidade ao Campo: a diversidade do saber-fazer turístico. Fortaleza: SENAC, 2003.

DEBORD, Guy. A sociedade do espetáculo. Rio de Janeiro: Contraponto, 1997.

DIAS, Reinaldo. O turismo religioso como segmento do mercado turístico. In: DIAS, Reinaldo; SILVEIRA, Emerson (orgs.). Turismo religioso: ensaios e reflexões. Campinas: Editora Alínea, 2003.

DUARTE, Rodrigo. Valores e interesses na era das imagens. In: NOVAES, Adauto (org.). Muito além do espetáculo. São Paulo: Editora SENAC, 2005. P.94-112.

ETGES, Virgínia Elisabeta. Turismo Rural: uma alternativa de desenvolvimento para comunidades rurais.

FUENTES, Ana Garcia de. Cancún: las sombras del paraíso (Mimeo).

HARVEY, David. O neoliberalismo: história e implicações. São Paulo: Edições Loyola, 2014.

JAPPE, Anselm. O reino da contemplação passiva. In: NOVAES, Adauto (org.). Muito além do espetáculo. São Paulo: Editora SENAC, 2005. P.254-275.

LIMONAD, Ester. "Você já foi à Bahia, nêga? Não! Então vá! Antes que acabe...". Planejamento, urbanização e turismo no litoral do Nordeste brasileiro, tendências e perspectivas. In: Revista Eletrónica de Geografía y Ciencias Sociales. Barcelona, 2008.

MESQUITA, Érika. Um Olhar Sócio-geográfico sobre o Turismo. In: Em Questão, Porto Alegre, V. 12, nº 2, jun/dez 2006.

MINISTÉRIO DO TURISMO. Turismo rural: orientações básicas. Brasília: Ministério do Turismo, 2010.

MINISTÉRIO DO TURISMO. Estatísticas e indicadores. 2019. Disponível em: http://www.dadosefatos.turismo.gov.br/ . Acesso em: 10 de outubro de 2019.

NEIMAN, Zysman. Ecoturismo e Educação Ambiental em Unidades de Conservação: a importância da experiência dirigida. In: Pelas trilhas do ecoturismo. São Carlos: RiMa, 2008.

NICOLAS, D.H. Elementos para un análisis sociogeográfico del turismo. In: RODRIGUES, A. B. (org). Turismo e geografia: reflexões teóricas e enfoque regionais. São Paulo: Hucitec, 2001.

NOVAES, Adauto. A imagem e o espetáculo. In: NOVAES, Adauto (org.). Muito além do espetáculo. São Paulo: Editora SENAC, 2005. P.8-15.

NUNES, Nathan da Silva. Imagem e representações nos cartões postais: a paisagem dos municípios de Armação dos Búzios, Casimiro de Abreu e Saquarema, na região das Baixadas Litorâneas. 2017. 109f. Dissertação (Mestrado em Geografia - PPGEO/UERJ). Rio de Janeiro, 2017. 
PAIVA, Ricardo Alexandre. Turismo, produção e consumo do espaço. In: VARGAS, Heliana Comin; PAIVA, Ricardo Alexandre (orgs.). Turismo, arquitetura e cidade. Barueri: Manole, 2016a. P.33-54.

PAIVA, Ricardo Alexandre. Os ícones urbanos e arquitetônicos. In: VARGAS, Heliana Comin; PAIVA, Ricardo Alexandre (orgs.). Turismo, arquitetura e cidade. Barueri: Manole, 2016b. P.289-314.

PANOSSO NETTO, Alexandre; NOGUERO, Felix Tomillo; JAGER, Margret. Por uma visão crítica nos estudos turísticos. In: PANOSSO, NETTO, Alexandre; NECHAR, Marcelino Castillo (editores). Turismo: perspectiva crítica. Textos reunidos. Assis: Triunfal Gráfica e Editora, 2016. P.157-179.

RIBEIRO, Miguel Angelo. Categorias analíticas do espaço e turismo: o exemplo da Fortaleza de Santa Cruz, Niterói/RJ. In: GEOgraphia. Ano VIII, nº 16, 2006. P.83-98.

RUSCHMANN, Doris van de M. O Turismo Rural e o Desenvolvimento Sustentável. SANTOS, Maria da Graça. A mobilidade religiosa em transformação: o turismo religioso. Portugal: Editora Princípia, 2006.

SOUZA, Marcelino de; KLEIN, Ângela Luciane; RODRIGUES, Renata Gonçalves. Turismo rural: conceitos, tipologias e funções. In: SOUZA, Marcelino de; DOLEI, Tissiane Schmidt (orgs.). Turismo rural: fundamentos e reflexões. Porto Alegre: Editora da UFRGS, 2019.

VARGAS, Heliana Comin. Turismo: reflexões disciplinares. In: VARGAS, Heliana Comin; PAIVA, Ricardo Alexandre (orgs.). Turismo, arquitetura e cidade. Barueri: Manole, 2016. P.3-32.

WOLFF, Francis. Por trás do espetáculo: o poder das imagens. In: NOVAES, Adauto (org.). Muito além do espetáculo. São Paulo: Editora SENAC, 2005. P.16-45.

WULF, Andrea. A invenção da natureza. A vida e as descobertas de Alexander Von Humboldt. São Paulo: Planeta, 2016. 